\title{
Laparoscopic hepatectomy for benign hepatic lesions: short and long-term outcomes including quality-of-life evaluation
}

\author{
Sergio Renato Pais-Costa ${ }^{1}$, Olímpia Alves Teixeira Lima ${ }^{2}$, Guilherme Crispim Costa ${ }^{3}$, Sandro José \\ Martins $^{4}$ \\ ${ }^{1}$ Hospital Brasilia and University Hospital of Brasilia, University of Brasilia, Brasília 70390-108, Federal District, Brazil. \\ ${ }^{2}$ Hospital Brasilia, University of Brasília, Brasília 70390-108, Federal District, Brazil. \\ ${ }^{3}$ Hospital Brasilia, Brasília 70390-108, Federal District, Brazil. \\ ${ }^{4}$ Ministry of Health, Brasília 70390-108, Federal District, Brazil.
}

Correspondence to: Dr. Sergio Renato Pais-Costa, Hospital Brasilia and University Hospital of Brasilia, University of Brasilia, SEPS 710/910, Sala 330, CEP: 70390-108 - Brasília - DF - Brazil. E-mail: srenatopaiscosta@hotmail.com

How to cite this article: Pais-Costa SR, Lima OAT, Costa GC, Martins SJ. Laparoscopic hepatectomy for benign hepatic lesions: short and long-term outcomes including quality-of-life evaluation. Mini-invasive Surg 2018;2:33.

http://dx.doi.org/10.20517/2574-1225.2018.33

Received: 31 May 2018 First Decision: 3 Jul 2018 Revised: 14 Sep 2018 Accepted: 17 Sep 2018 Published: 29 Sep 2018

Science Editor: Fernando Andrés Alvarez Copy Editor: Yuan-Li Wang Production Editor: Zhong-Yu Guo

\begin{abstract}
Aim: Even though laparoscopic hepatectomy (LH) has proved to be both safe and effective in specialized centers; the restricted indications for resection in the case of benign liver lesions has resulted in poorly reported outcomes. Our aim was to describe the short and long-term results of LH to treat benign hepatic lesions, including quality of life (QoL) evaluation.
\end{abstract}

Methods: Thirty-one LHs were performed between 2007 and 2018 in 30 patients. We evaluated QoL with the SF-36 test and a body image satisfaction questionnaire by personal interview before surgical treatment and at 1 month, 3 months, 6 months and 1 year after surgery.

Results: Median age was 38 years (range 21-71) and the majority were females (68\%). The most frequent etiology was hepatic adenoma in 16 patients (52\%), followed by focal nodular hyperplasia $(n=4)$, cavernous hemangioma $(n=3)$, hepatic abscess $(n=3)$, cystadenoma $(n=5)$ and hepatolithiasis $(n=1)$. The majority of resections were minor $(66 \%)$ and the conversion rate was $6.2 \%$. Pathological examination confirmed negative margins in all patients. Postoperative mortality was nil, while morbidity was $6.2 \%$. Median hospital stay was 4 days (range 1-32 days). In a median follow-up of 48 months (range 2-120), 2 patients experienced recurrence. QoL variables were similar between the preoperative and postoperative periods.

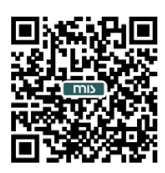


Conclusion: LH should be considered the main therapeutic approach for treating selected patients with benign liver lesions who require surgical resection because it presented both null mortality and low morbidity, along with rare recurrence, a good quality of life and high esthetic satisfaction.

Keywords: Laparoscopic liver surgery, liver neoplasms, adenoma, liver cell, focal nodular hyperplasia, hemangioma, cavernous, quality of life

\section{INTRODUCTION}

Since the early 90s, when the first laparoscopic anatomical resection of the liver was reported, laparoscopic hepatectomy $(\mathrm{LH})$ has gained increasing importance for treating hepatic tumors ${ }^{[1]}$. Several advances in laparoscopic instruments such as parenchymal transection devices, staplers and hand-assisted equipment, together with improved expertise in laparoscopic surgery, have led to increasing use of LH, especially in referral centers. Given its many advantages over open hepatectomy, including less postoperative pain, less use of opiate analgesia, better cosmetic results, decreased blood loss, decreased postoperative complications (both hepatic-specific and pulmonary) and shorter hospital stay, LH has become the preferred approach for treating benign hepatic tumors ${ }^{[2-7]}$. Even though LH has been shown to be both safe and effective; the restricted indications for resection in the case of benign liver lesions have resulted in poorly reported longterm outcomes. In addition, there is a need to know whether LH might improve the overall postoperative quality of life (QoL) of patients with benign lesions ${ }^{[8-15]}$.

The aim of the present study was to evaluate the short and long-term outcomes of LH for benign liver tumors, with special emphasis on postoperative QoL results.

\section{METHODS}

Between June 2007 and March 2018, 81 LHs were performed by a single surgical team in two hospitals (Hospital Santa Lucia between 2007 and 2014 followed by Hospital Brasilia between 2014 and 2018). Of these, 31 (38\%) LHs performed in 30 patients bearing benign hepatic lesions formed the study population.

The indications for resection of benign liver lesions were as follows: symptomatic patients, presence of cystadenoma, presence of hepatolithiasis and uncertain diagnosis based either on imaging or on biopsy findings (when it was not possible to rule out malignant hepatic neoplasm). Hepatic adenoma (HA) was also resected in the following circumstances: larger than $4-5 \mathrm{~cm}$, female gender with intention to conceive, presence of beta-catenin mutation or male gender. Resection of pyogenic liver abscess (PLA) was indicated after failure of percutaneous drainage. All patients were studied with serum tumor markers (CEA, AFP and Ca 19.9), abdominal ultrasonography, computed tomography and magnetic resonance imaging (MRI). For the last seven cases, MRI with hepatobiliary contrast (Primovist; Bayer-Schering, Berlin, Germany) was also carried out. Since 2007, our team has considered the laparoscopic approach as the first choice for all hepatectomies except in the following situations: very large lesions $(>10 \mathrm{~cm})$ in the right lobe, tumors close to major vascular structures, or central locations. All liver resections were defined in accordance with the International Hepato-Pancreato-Biliary Association terminology through the Brisbane Nomenclature, 2000. Major hepatectomy was defined as resection of three or more hepatic segments. The surgical techniques used for LH were either the intra-hepatic Glissonian approach [Figures 1 and 2] or the extra-hepatic Glissonian approach [Figures 3 and 4], in accordance with previous standardization ${ }^{[7,11-13]}$. Intraoperative ultrasonography was performed whenever available. Surgical specimens were preferentially removed in an Endobag [Figure 5], by means of a Pfannenstiel incision [Figure 6] or a small right subcostal incision. On the liver bed, a hemostatic Surgicel was used, along with fibrin glue (Eviscel) when available, to finish the hemostasis. Finally, drains were placed only for major hepatectomies. Postoperative morbidity 


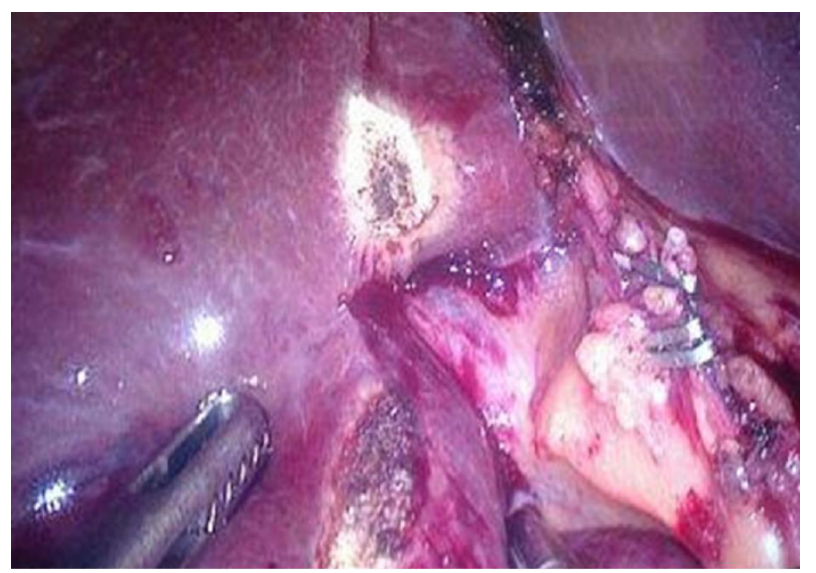

Figure 1. Intrahepatic Glissonian approach for right posterior sectionectomy. Demarcation of liver surface around right posterior Glissonian pedicle

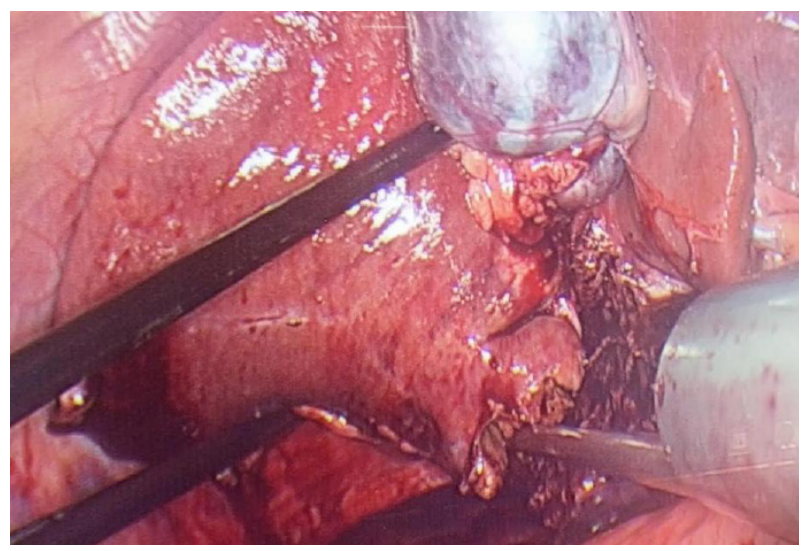

Figure 2. Intrahepatic Glissonian approach for right hepatectomy. En-bloc stapling of right glissonian pedicles by means of vascular stapler (after two hepatotomy procedures)

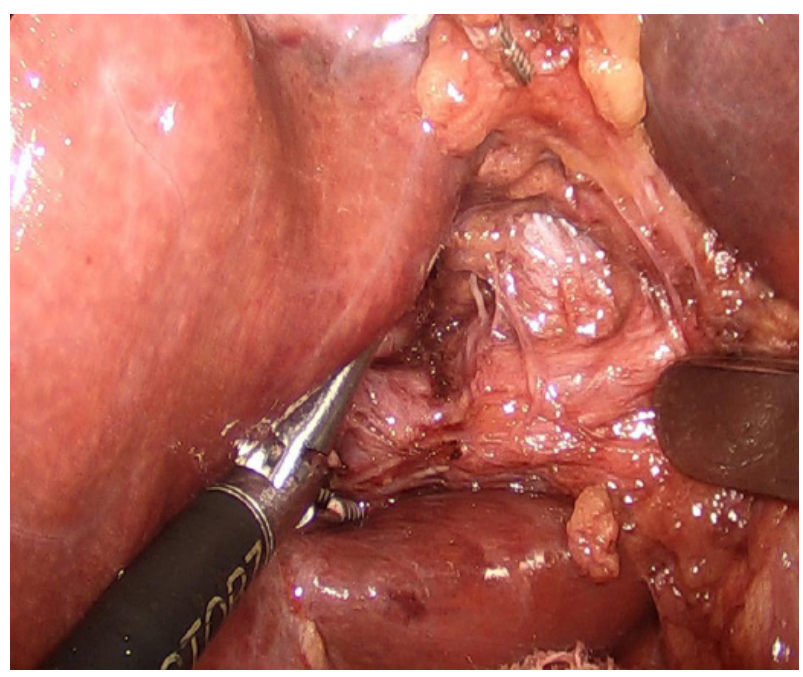

Figure 3. Extra-hepatic approach. En-bloc dissection of the right posterior hepatic pedicle 


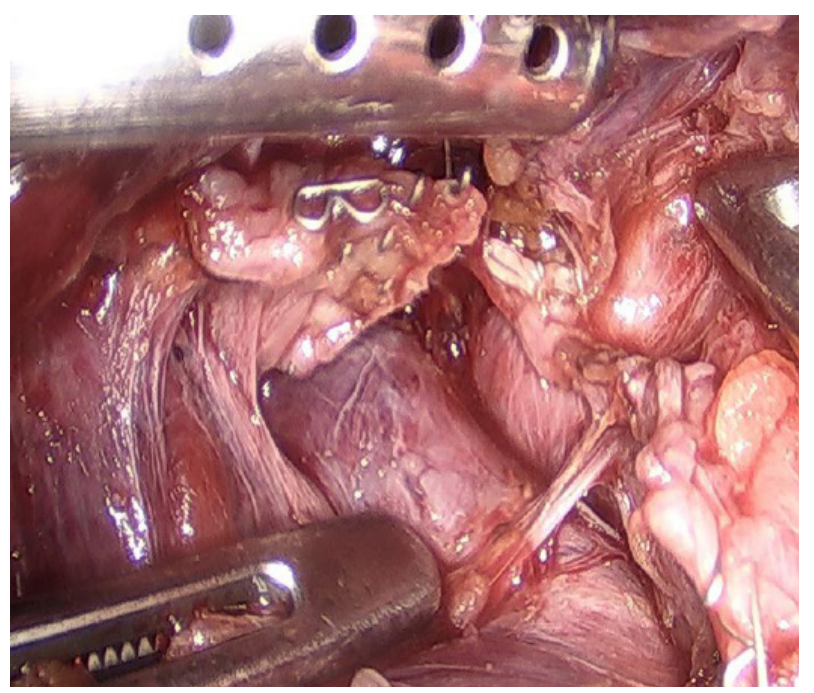

Figure 4. Extra-hepatic approach. Right posterior hepatic pedicle stapled en-bloc

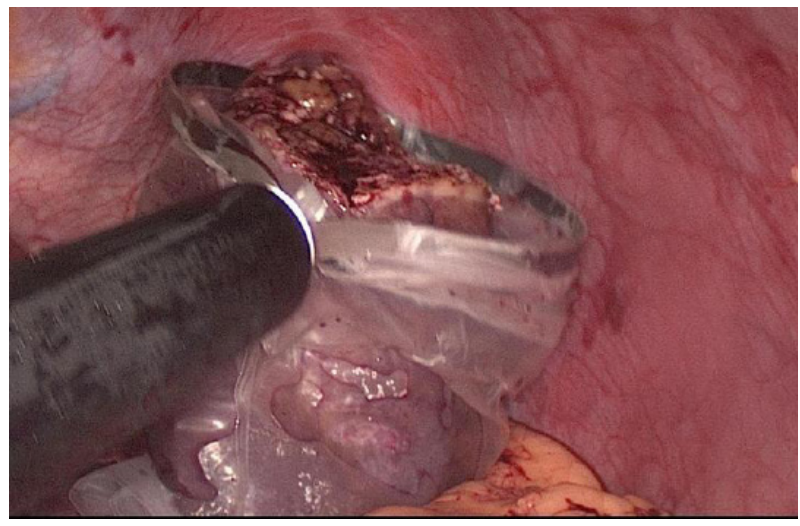

Figure 5. Segmentectomy 3 surgical specimen placed in Endobag before retrieval

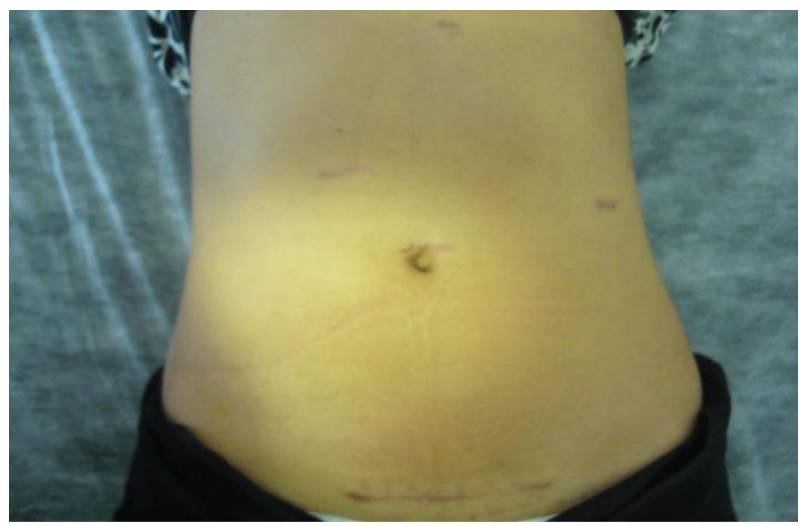

Figure 6. Late result after left lateral laparoscopic segmentectomy 
Table 1. Patient Characteristics

\begin{tabular}{ll}
\hline Variable & Value \\
\hline Gender, female, $n$ (\%) & $21(70)$ \\
Age, years, median (range) & $38(21-71)$ \\
ASA risk score, $n$ (\%) & \\
1 & $28(93)$ \\
2 & $2(7)$ \\
3 & \\
Previous open abdominal surgery, $n(\%)$ & $6(20)$ \\
Etiology, $n$ (\%) & \\
Adenoma & $16(50)$ \\
Cystadenoma & $5(17)$ \\
Focal nodular hyperplasia & $4(13)$ \\
Pyogenic liver abscess & $3(10)$ \\
Hemangioma & $3(10)$ \\
Non-oriental hepatolithiasis & $1(3)$ \\
Number of lesions, median (range) & $1(1-6)$ \\
Lesions size, cm, median (range) & $5(3-13)$ \\
\hline
\end{tabular}

was defined in accordance with the Clavien-Dindo classification of surgical complications ${ }^{[16]}$. Biliary fistula was defined using the International Study Group of Liver Surgery classification ${ }^{[17]}$. Follow-up included physical examinations and hepatic blood tests every three months, as well as abdominal imaging (CT or MRI) twice a year. Recurrence was considered when a lesion reappeared on imaging examinations and was finally confirmed by means of histological analysis. QoL was measured by means of a QoL questionnaire using the Short-Form Health Survey (SF 36), as previously reported by Giuliani et al. ${ }^{[15]}$. This test was administered by means of a personal interview before surgery and at 1, 3, 6 and 12 months after surgery. In addition, a simple non-validated questionnaire was also performed including the following questions: (1) satisfaction of surgical scar; (2) exposure of body image when wearing bikinis, shorts, "summer clothes", etc.; (3) change of daily behavior (social, type of the clothes, sportive practices); and (4) recommendation of the LH to other patients. The responses were classified into positive or negative. All these questions were considered to evaluate body image satisfaction regarding the esthetics aspects after $\mathrm{LH}$.

\section{Statistical Analyses}

Categorical variables are described using percentages. Continuous variables are expressed as means and standard deviation for symmetrically distributed, and median (range) for nonsymmetrically distributed data. Differences in SF-36 QoL questionnaire scores between preoperative evaluations and postoperative evaluations were analyzed using two-way repeated measures ANOVA and each patient was in his or her own control at the time of the evaluation. There were no significant outliers in pairwise comparisons and normality assumption held at Shapiro-Wilk test using residuals. We used Wilks' lambda as an omnibus test statistics for differences between the means of QoL evaluations. Within-subjects effects were evaluated by F-test with Greenhouse-Geisser correction due to unequal variances of the differences between all combinations of related groups, as assessed by Mauchly's test. Post hoc pairwise comparisons were calculated with Bonferroni adjustment for multiple comparisons. We reported exact $\mathrm{P}$ values up to 0.001 and the significance level was set to 0.05 (5\%) for statistical inference. Statistical analyses were performed using PASW Statistics 18 (SPSS Inc., Hong Kong, 2015).

\section{RESULTS}

The general characteristics of the study population are detailed in Table 1. Median age was 38 years (range 21-71) and the majority were females (70\%). The most frequent etiology was HA in 16 patients (50\%). Among symptomatic patients $(n=3)$ who underwent $\mathrm{LH}$, two of them had giant hepatic hemangiomas while the third patient had a giant focal nodular hyperplasia (FNH). Their symptoms were as follows: 
Table 2. Operative characteristics and postoperative outcomes

\begin{tabular}{ll}
\hline Variable & Value \\
\hline Type of hepatectomy, $n$ (\%) & $4(12.9)$ \\
Right hepatectomy & $6(19.3)$ \\
Left hepatectomy & $8(25.8)$ \\
RPS & $8(25.8)$ \\
LLS & $2(6.4)$ \\
Segmentectomy 5 & $1(3.2)$ \\
Segmentectomy 6 & $1(3.2)$ \\
Segmentectomy 3 & $1(3.2)$ \\
Segmentectomy 2 & $135(60-265)$ \\
Operative time, min, median (range) & $125(0-1000)$ \\
Blood loss, mL, median (range) & $2(6.2)$ \\
Major morbidity, $n$ (\%) & $0(0)$ \\
Mortality, $n$ (\%) & $4(1-32)$ \\
Hospital stay, days, median (range) & $14(7-32)$ \\
Time to normal activities, days, median (range)
\end{tabular}

RPS: right posterior sectionectomy; LLS: left lateral sectionectomy

abdominal pain and sensation of epigastric fullness $(n=2)$ and visceral compression $(n=1)$. For most patients, preoperative diagnosis was made from typical findings seen on either CT or MRI. Three patients with HA underwent a percutaneous biopsy that confirmed the presence of beta-catenin mutation. One patient underwent intraoperative frozen-section biopsy because preoperative examinations presented a differential diagnosis with hepatocellular carcinoma, and FNH was then confirmed in this case. There were 3 patients who presented multiple lesions, 1 patient had 6 lesions (FNH) and 2 patients had 3 lesions each (HA).

Thirty-one liver resections were performed in 30 patients (1 patient underwent 2 independent resections, both of them by means of a laparoscopic approach). The majority of liver resections were minor (64.5\%) and there were two open conversions in this series (6.4\%). One patient underwent conversion due to severe intraoperative bleeding $(>750 \mathrm{~mL})$ and the other due to technical difficulties. The first was an obese male operated on for a $10 \mathrm{~cm}$ symptomatic giant hemangioma in the dome of the left liver, very close to the left hepatic vein, which was injured due to a stapler failure. The stapler was fired but it was not possible to open it and, thus, an open repair became necessary. This patient was the only one in this series who required postoperative blood transfusions (3.3\%). The second case was a female with a cystadenoma in the left lobe who presented multiple adhesions between the small intestine and the liver due to a previous surgery. Pringle maneuver was performed in a single case who underwent open conversion due to intraoperative bleeding. Eight patients underwent surgical drainage of the liver bed by means of a tubular drain. Details of the surgical procedures are shown in Table 2.

Two patients (6.4\%) presented postoperative complications (grade 3), and these were the same 2 patients who underwent open conversion [Table 2]. One patient presented a biliary fistula that required endoscopic retrograde cholangiopancreatography with stent placement, and the other developed an incisional hernia that required a laparoscopic repair six months after surgery. There was no gas embolism in this series. Mortality was nil. The median hospital stay was 4 days (range 1-32 days) for the overall series, and 2 days (range 1-3 days) considering only the minor resections. Eighteen patients required low doses of common analgesics for 2 or 3 days during their postoperative course, while 10 patients required them for 4 days and 2 patients for 6 days. Both patients who underwent open conversion required narcotic analgesia. The median length of time taken to return to normal daily activities was 14 days (range 7-32 days) for the overall series, and 9 days (range 7-12 days) considering only the cases of monosegmentectomy. These findings are shown in Table 2 . Among the symptomatic patients, all of them achieved complete symptom 
relief. Histological examination confirmed negative surgical margins in all patients. Preoperative diagnosis was confirmed in all but 2 patients (93\%), who underwent oncological LH because of typical features of hepatocellular carcinoma on preoperative imaging (wash-in/wash-out), but definitive pathological evaluation showed HA in both cases. The median length of follow-up in this series was 48 months (range 2-120 months). Two patients experienced disease recurrence during follow-up. The first recurrence occurred in a young woman two years after right posterior sectionectomy due to HA. She developed a new HA in the left lobe and finally underwent a successful laparoscopic resection of segment III. The second recurrence occurred ten years after left hepatectomy for PLA in a 78-year-old man. He presented a new very large solid-cystic abscess in the right hepatic lobe (segments 7 and 8), for which he underwent open unroofing and finally died due to postoperative infectious complications and sepsis.

We observed a statistically significant decrease of the overall QoL in seven measured variables (except social) at early postoperative period until one month [Table 3]. However, after one month of the postoperative period we observed a statistically significant increase of the all Qol variables. Thus all Qol variables were similar between the preoperative and postoperative periods after 3 months from surgical intervention. These variables were maintained similar until 12 months. Both role emotional and mental health variables presented a great improvement after postoperative period [Table 3]. Application of the questionnaire to evaluate esthetic body image after surgery showed that $93 \%$ of the patients considered that their result was satisfactory. Only the two patients who underwent open conversion were dissatisfied with their esthetic result.

\section{DISCUSSION}

Since initial experiences, $\mathrm{LH}$ has been proven to be a good choice for treating benign hepatic lesions, especially for minor resections of lesions arising in easily accessible hepatic segments at anterolateral positions, so-called "laparoscopic hepatic segments" ${ }^{\text {s[-6] }}$. Since 2008 , two major international expert consensus conferences have been held to review the role of LH. The first of these was held in Louisville, USA, where it was established that LH was best indicated for solitary lesions measuring $5 \mathrm{~cm}$ or less that were located in segments 2 to $6^{[6]}$. At this meeting, it was accepted that laparoscopy should be considered the standard approach for left lateral sectionectomy and that indications for surgical treatment of benign hepatic lesions should not be widened simply because laparoscopic approach was feasible. Six years later, a new consensus meeting involving many worldwide experts was held in Morioka, Japan, where hepatic resections of greater complexity became more accepted, including major resections or resections of posterosuperior liver segments, especially at referral centers ${ }^{[7]}$. Therefore, LH is nowadays considered a safe and feasible alternative to open operations, even for left or right major hepatectomies and malignant liver lesions.

Given that LH is a complex laparoscopic procedure, laparoscopic left lateral sectionectomy has been considered by many experts the ideal anatomical resection for initial training because of its anatomical accessibility and the possibility of using the aid of staplers ${ }^{[18-22]}$. Therefore, laparoscopic left lateral sectionectomy has been one of the most performed types of LH along the learning curve of many authors $^{[8,10,12]}$. Even though laparoscopic left lateral sectionectomy and right posterior sectionectomy were the most frequent LHs performed in the present series, more complex LHs including left hepatectomy, right hepatectomy and even mesohepatectomy were also performed, reflecting the strong trend in the literature towards performing more complex procedures for treating hepatic lesions ${ }^{[2-13,15,23]}$.

Many studies, including meta-analyses, have confirmed the benefits of LH in comparison with open hepatectomy, namely: lower levels of postoperative pain, fewer peritoneal adhesions, shorter hospital stay, earlier return to daily activities, lower blood loss, reduced morbidity, fewer operative complications and less mortality ${ }^{[2-15,18-29]}$. Among the short-term outcomes from our study, a low blood loss (mean $125 \mathrm{~mL}$ ), 
Table 3. QoL variables

\begin{tabular}{|c|c|c|c|c|c|c|}
\hline Dimension & Time & Mean (SD) & Multivariate model $^{a}$ & Within subjects $^{\mathrm{b}}$ & Baseline contrast $^{c}$ & Last period contrast $^{\mathrm{c}}$ \\
\hline \multirow[t]{5}{*}{ Physical functionating } & Baseline & $96.9(2.5)$ & $<0.001$ & $<0.001$ & & \\
\hline & $1 \mathrm{mo}$ & $93.1(5.5)$ & & & 0.002 & 0.002 \\
\hline & $3 \mathrm{mo}$ & $94.7(5.2)$ & & & 0.22 & 0.001 \\
\hline & $6 \mathrm{mo}$ & $95.5(4.9)$ & & & 0.98 & 0.004 \\
\hline & $12 \mathrm{mo}$ & $96.4(3.9)$ & & & 1.00 & 0.39 \\
\hline \multirow[t]{5}{*}{ Social functionating } & Baseline & $99.4(0.7)$ & 0.48 & & & \\
\hline & $1 \mathrm{mo}$ & $98.8(2.9)$ & & & & \\
\hline & $3 \mathrm{mo}$ & $99.3(1.3)$ & & & & \\
\hline & $6 \mathrm{mo}$ & $99.6(0.7)$ & & & & \\
\hline & $12 \mathrm{mo}$ & $99.7(0.6)$ & & & & \\
\hline \multirow[t]{5}{*}{ Mental health } & Baseline & $91.7(5.1)$ & $<0.001$ & $<0.001$ & & \\
\hline & $1 \mathrm{mo}$ & $93.2(8.1)$ & & & 1.00 & 1.00 \\
\hline & $3 \mathrm{mo}$ & $95.8(4.2)$ & & & 0.002 & 0.29 \\
\hline & $6 \mathrm{mo}$ & $97.9(2.5)$ & & & $<0.001$ & 0.023 \\
\hline & $12 \mathrm{mo}$ & $97.2(3)$ & & & $<0.001$ & 1.00 \\
\hline \multirow[t]{5}{*}{ Bodily pain } & Baseline & $97.4(2.2)$ & $<0.001$ & 0.032 & & \\
\hline & $1 \mathrm{mo}$ & $95.4(6.2)$ & & & 0.81 & 0.81 \\
\hline & $3 \mathrm{mo}$ & $96.5(4.5)$ & & & 1.00 & 0.40 \\
\hline & $6 \mathrm{mo}$ & $97.6(2.8)$ & & & 1.00 & 0.09 \\
\hline & $12 \mathrm{mo}$ & $97.6(2.8)$ & & & 1.00 & 1.00 \\
\hline \multirow[t]{5}{*}{ Vitality } & Baseline & $97.6(4.5)$ & 0.009 & 0.001 & & \\
\hline & $1 \mathrm{mo}$ & $96.4(4.8)$ & & & 0.29 & 0.29 \\
\hline & $3 \mathrm{mo}$ & $95.7(5)$ & & & 0.044 & 1.00 \\
\hline & $6 \mathrm{mo}$ & $97.2(3.4)$ & & & 1.00 & 0.007 \\
\hline & $12 \mathrm{mo}$ & $98.5(2.1)$ & & & 1.00 & 0.035 \\
\hline \multirow[t]{5}{*}{ Role physical } & Baseline & $93.1(2.9)$ & 0.008 & $<0.001$ & & \\
\hline & $1 \mathrm{mo}$ & $90.3(5.6)$ & & & 0.01 & 0.01 \\
\hline & $3 \mathrm{mo}$ & $92.4(3.8)$ & & & 1.00 & 0.003 \\
\hline & $6 \mathrm{mo}$ & $92.8(3.4)$ & & & 1.00 & 1.00 \\
\hline & $12 \mathrm{mo}$ & $93.8(2.9)$ & & & 1.00 & 0.13 \\
\hline \multirow[t]{5}{*}{ Role emotional } & Baseline & $89.5(7.1)$ & $<0.001$ & $<0.001$ & & \\
\hline & $1 \mathrm{mo}$ & $93.2(5.2)$ & & & 0.45 & 0.45 \\
\hline & $3 \mathrm{mo}$ & $95.9(3.6)$ & & & 0.005 & 0.69 \\
\hline & $6 \mathrm{mo}$ & $96.4(3.1)$ & & & 0.001 & 0.99 \\
\hline & $12 \mathrm{mo}$ & $97.3(2.7)$ & & & $<0.001$ & 0.08 \\
\hline \multirow[t]{5}{*}{ General health } & Baseline & $95.6(7.6)$ & $<0.001$ & 0.037 & & \\
\hline & $1 \mathrm{mo}$ & $97.5(1.2)$ & & & 1.00 & 1.00 \\
\hline & $3 \mathrm{mo}$ & $98.7(1.2)$ & & & 0.26 & $<0.001$ \\
\hline & $6 \mathrm{mo}$ & $99.1(0.8)$ & & & 0.11 & 0.61 \\
\hline & $12 \mathrm{mo}$ & $99.4(0.9)$ & & & 0.24 & 0.83 \\
\hline
\end{tabular}

${ }^{a}$ Wilks' lambda; ${ }^{b}$ F-test with Greenhouse-Geisser correction for violation of sphericity; ${ }^{c}$ post hoc pairwise comparisons with Bonferroni adjustment for multiple comparisons. SD: standard deviation

short hospital stay, low morbidity (6.4\%) and no mortality are clearly in accordance with the many advantages reported in previous studies. The surgical margin was adequate in all cases, despite the lack of intraoperative palpation that is inherent to this method. Late recurrence in this series was a rare event (only $6 \%$ ), and given that they occurred distant in liver parenchyma, they could perhaps be attributed to more aggressive biological behavior in those two cases.

Benign lesions of the liver usually occur in young patients, who care not only to achieve an early return to work and sports practice, but also to maintain a good QoL and a pleasing body image. Giuliani et al. ${ }^{[15]}$ have demonstrated that the laparoscopic approach was superior regarding the QoL of patients who underwent operations due to benign liver lesions. In the present study we observed that there was an excellent 
QoL among the patients who underwent successful LH without open conversion. Seven out of eight variables measured by the SF 36 questionnaire presented similar results between preoperative period and postoperative period (after three months of surgical procedure). In our view point, this finding may indicate that LH allows QoL maintenance in patients operated from benign diseases. In the present study, an early return to work and sports practice was observed and, since most of the patients were young and in a productive phase of their lives, a significant socioeconomic gain could be expected from this population group. The main limitations of this study are its retrospective nature, as well as the heterogeneous and relatively small patient population. However, to our knowledge, no case series in Brazil have evaluated early and late postoperative outcomes along with the QoL of patients after LH performed solely on benign lesions of the liver. In addition, this report is unique because most of the patients in this sample were young women who live in a tropical country where body image is a very important tool for evaluating the overall QoL. Thus, a simple satisfaction questionnaire was applied in addition to the QoL questionnaire and showed that about $93 \%$ of our patients were satisfied in relation to the general esthetic aspects of the laparoscopic approach.

In conclusion, LH presented low morbidity, null mortality and rare recurrence in the present series. Furthermore, LH offered a good QoL and high esthetic satisfaction. Therefore, LH performed by expert liver surgeons should be considered the main therapeutic approach for treating selected patients with benign liver lesions who require surgical resection. Further prospective studies are needed to confirm our findings.

\section{DECLARATIONS}

\section{Author's contributions}

Contribution to conception and design, and analysis and interpretation of data, giving the final approval of the version to be submitted and any revised version: Pais-Costa SR

Contribution to selection of the studies and literature which were included in the references and drafting the article and revising it critically for important intellectual content: Lima OAT

Contribution with acquisition and collection of data: Costa GC

Contribution to statistical analyses : Martins SJ

\section{Availability of data and materials}

Data of the patients were collected from their archives in Dr. Pais-Costa's personal clinic, Oncodigestiva Digestive Surgery Institute. The patients only authorized this study.

\section{Financial support and sponsorship}

None.

\section{Conflicts of interest}

All authors declared that there were no conflicts of interest.

\section{Ethical approval and consent to participate}

This study was approved by hospital ethics committee of Hospital Brasília. Consent to participate was obtained.

\section{Consent for publication}

Not applicable.

\section{Copyright}

(c) The Author(s) 2018. 


\section{REFERENCES}

1. Azagra JS, Gowergen M, Gilbart E, Jacobs D. Laparoscopic anatomical (hepatic) left lateral segmentectomy-technical aspects. Surg Endosc 1996;10:768-61.

2. Buell JF, Tranchart H, Cannon R, Dagher I. Management of benign hepatic tumors. Surg Clin North Am 2010;90: 719-35.

3. Abu Hilal M, Di Fabio F, Teng MJ, Godfrey DA, Primrose JN, Perace NW. Surgical management of benign and indeterminate hepatic lesions in the era of laparoscopic liver surgery. Dig Surg 2011; 28: 232-6.

4. Cugat E, Marco C. Cirugía laparoscópica del hígado. Una opción madura? Cir Esp 2009;85:193-5.

5. Edwin B, Nordin A, Kazaryan AM. Laparoscopic liver surgery: new frontiers. Scan J Surg 2011;100:54-65.

6. Buell JF, Cherqui D, Geller DA, O'Rourke N, Iannitti D, Dagher I, Koffron AJ, Thomas M, Gayet B, Han HS, Wakabayashi G, Belli G, Kaneko H, Ker CG, Scatton O, Laurent A, Abdalla EK, Chaudhury P, Dutson E, Gamblin C, D’Angelica M, Nagorney D, Testa G, Labow D, Manas D, Poon RT, Nelson H, Martin R, Clary B, Pinson WC, Martinie J, Vauthey JN, Goldstein R, Roayaie S, Barlet D, Espat J, Abecassis M, Rees M, Fong Y, McMasters KM, Broelsch C, Busuttil R, Belghiti J, Strasberg S, Chari RS; World Consensus Conference on Laparoscopic Surgery. The international position on laparoscopic liver surgery: the Louisville statement, 2008. Ann Surg 2009;250:825-30.

7. Wakabayashi G, Cherqui D, Geller DA, Buell JF, Kaneko H, Han HS, Asbun H, O'Rourke N, Tanabe M, Koffron AJ, Tsung A, Soubrane O, Machado MA, Gayet B, Troisi RI, Pessaux P, Van Dam RM, Scatton O, Abu Hilal M, Belli G, Kwon CH, Edwin B, Choi GH, Aldrighetti LA, Cai X, Cleary S, Chen KH, Schön MR, Sugioka A, Tang CN, Herman P, Pekolj J, Chen XP, Dagher I, Jarnagin W, Yamamoto M, Strong R, Jagannath P, Lo CM, Clavien PA, Kokudo N, Barkun J, Strasberg SM. Recommendations for laparoscopic liver resection: a report from the second international consensus conference held in Morioka. Ann Surg 2015;261:619-29.

8. Pais-Costa SR, Araujo SL, Lima OA, Teixeira AC. Laparoscopic hepatectomy: indications and results from 18 resectable cases. Einstein (Sao Paulo) 2011;9:343-9.

9. Machado MAC, Makdissi FF, Surjan RCT. Hepatectomia videolaparoscópica: experiência pessoal com 107 casos. Rev Col Bras Cir 2012;39:483-8.

10. Herman P, Coelho FF, Perini MV, Lupinacci RM, D’Albuquerque LA, Cecconello I. Hepatocellular adenoma: an excellent indication for laparoscopic liver resection. HPB (Oxford) 2012;14:390-5.

11. Lacerda CF, Bertulucci PA, Oliveira AT. Totally laparoscopic liver resection: new Brazilian experience. Arq Bras Cir Dig 2014;27:1915.

12. Pais-Costa SR, Araújo SLM, Lima OAT, Martins SJ. Critical evaluation of long-term results of malignant hepatic tumors treated by means curative laparoscopic hepatectomy. Arq Bras Cir Dig 2017;30:205-10.

13. Pais-Costa SR, Araújo SLM, Teixeira OA, Pereira AC. Laparoscopic right posterior sectioniectomy for treating hepatic tumors. Arq Bras Cir Dig 2010;23: 275-9.

14. Pais-Costa SR, Araujo SLM, Lima OAT. Intrahepatic glissonian approach for laparoscopic left lateral segmentectomy: is it worthwhile? Report on six cases. Bras J Video-Sur 2011;4: 217-23.

15. Giuliani A, Migliaccio C, Ceriello A, Aragiusto G, La Manna G, Calise F. Laparoscopic vs. open surgery for treating benign lesions: assesing quality life in the first year after surgery. Updates Surg 2014;66:127-33.

16. Dindo D, Demartines N, Clavien PA. Classification of surgical complications: a new proposal with evaluation in a cohort of 6336 patients and results of survey. Ann Surg 2004;240:205-13.

17. Koch M, Garden OJ, Padbury R, Rahbari NN, Adam R, Capussotti L, Fan ST, Yokoyama Y, Crawford M, Makuuchi M, Christophi C, Banting S, Brooke-Smith M, Usatoff V, Nagino M, Maddern G, Hugh TJ, Vauthey JN, Greig P, Rees M, Nimura Y, Figueras J, DeMatteo RP, Büchler MW, Weitz J. Bile Leakage after hepatobiliary and pancreatic surgery: a definition and grading of severity by the international study group of liver surgery. Surgery 2011;149:680-8.

18. Robles Campos R, Marín Hernández C, López Conesa A, Abellán B, Pastor Pérez P, Parrilla Paricio P. Laparoscopic resection of the left segments of the liver: the "ideal technique" in experienced centres? Cir Esp 2009;85:214-21.

19. Carswell KA, Sagias FG, Murgatroyd B, Rela M, Heaton N, Patel AG. Laparoscopic versus open left lateral segmentectomy. BMC Surg 2009;9:14.

20. Chang S, Laurent A, Tayar C, Karoui M, Cherqui D. Laparoscopic as a routine approach for left lateral sectionectomy. Br J Surg 2007:94:58-63.

21. Cugat E, Marco C. Laparoscopic liver surgery. A mature option? Cir Esp 2009;85:193-5.

22. Liu Z, Ding H, Xiong X, Huang Y. Laparoscopic left lateral hepatic sectioniectomy was expected to be the standard for the treatment of left hepatic lobe lesions: a meta-analysis. Medicine (Baltimore) 2018;97:e9835.

23. de'Angelis N, Memeo R, Calderaro J, Felli E, Salloum C, Compagnon P, Luciani A, Laurent A, Cherqui D, Azoulay D. Open and laparoscopic resection of hepatocellular adenoma: trends over 23 years at a specialist hepatobiliary unit. HPB (Oxford) 2014;16:783-8.

24. Chen K, Pan Y, Zhang B, Liu XL, Maher H, Zheng XY. Laparoscopic versus open surgery for hepatocellular carcinoma: a meta-analysis of high-quality case-matched studies. Can J Gastroenterol Hepatol 2018;2018:1746895.

25. Guo Y, Gao Y, Chen G, Li C, Dong G. Minimally invasive versus open simultaneous resections of colorectal cancer and synchronous liver metastases: a meta-analysis. Am Surg 2018;84:192-200.

26. Coelho FF, Bernardo WM, Kruger JAP, Jeismann VB, Fonseca GM, Macacari RL, Cesconetto DM, D'Albuquerque LAC, Cecconello I, Herman P. Laparoscopic-assisted versus open and pure laparoscopic approach for liver resection and living donor hepatectomy: a systematic review and meta-analysis. HPB (Oxford) 2018;20:687-94.

27. Kasai M, Cipriani F, Gayet B, Aldrighetti L, Ratti F, Sarmiento JM, Scatton O, Kim KH, Dagher I, Topal B, Primrose J, Nomi T, Fuks D, Abu Hilal M. Laparoscopic versus open major hepatectomy: a systematic review and meta-analysis of individual patient data. Surgery 2018;163:985-95. 
28. Liu X, Min X, Ma Z, He X, Du Z. Laparoscopic hepatectomy produces better outcomes for hepatolithiasis than open hepatectomy: an updated systematic review and meta-analysis. Int J Surg 2018;51:151-63.

29. Liu H, Wang D, Yu Y, Ren H, Jiang T. Meta-analysis of efficacy of laparoscopic hepatectomy versus open hepatectomy for hepatocarcinoma. J cancer Res Ther 2017;13:849-55. 